\title{
ESTUDO GEORREFERENCIADO DO PERFIL DE DESLOCAMENTO DOS ALUNOS DE UMA UNIVERSIDADE PRIVADA
}

\author{
Pedro Otavios da Silva Vieira Costa \\ Cleiton de Souza Oliveira \\ Raquel Cymrot \\ Sergio Vicente Denser Pamboukian
}

Universidade Presbiteriana Mackenzie (UPM)

\section{Resumo}

A mobilidade urbana tem se mostrado cada vez mais um problema para grandes metrópoles, uma vez que o tempo gasto no deslocamento afeta a qualidade de vida da populaçáo e a economia da regiáo. Para diminuir o tempo de deslocamento, a gestáo da rede de transporte precisa, em primeiro lugar, reunir informaçóes a respeito do perfil de deslocamento da população e, em seguida, tomar decisóes para projetos futuros ou para a melhoria da rede já existente. A partir de informaçóes estatísticas e da utilização de software de geoprocessamento, como o Sistemas de Informaçôes Geográficas (GIS), é possível uma melhor visualização e identificação das regiōes carentes de transportes ou de qualquer outro fator que influencie a mobilidade, como a segurança e a oferta de transporte público. Na Região Metropolitana de São Paulo (RMSP), é conduzida a pesquisa Origem-Destino com o objetivo de coletar dados referentes às características da populaçáo e ao seu perfil de deslocamento. A pesquisa realizada por Oliveira e Cymrot (2017) sobre o perfil de deslocamento de alunos de uma universidade privada foi usada como fonte secundária de dados deste artigo, especialmente dados como a localização do indivíduo, o modal utilizado e o relato afirmativo ou negativo sobre o assédio sexual no transporte público. A partir dos dados estatísticos coletados, buscou-se complementá-los com o georreferenciamento de algumas 
informaçôes, permitindo melhor visualização. Para a realização do georreferenciamento, foi utilizado o software QGIS versão 2.18, que permitiu a elaboração dos mapas deste estudo, de modo a facilitar a caracterização de um polo gerador de tráfego. Os mapas gerados possibilitaram a análise da posição dos alunos, relacionando a distância deles em relação à universidade e ao sistema metroviário ou ferroviário, além da possibilidade de observar com mais facilidade as regióes de alta concentração de alunos nos diferentes modais.

Palavras-chave: Georreferenciamento. Mobilidade urbana. Universidade.

\section{INTRODUÇÁO}

A mobilidade urbana é um tema relevante em qualquer lugar do mundo, pois o deslocamento de pessoas ou mercadorias é a essência do funcionamento e desenvolvimento socioeconômico de uma cidade. Devido à sua relevância na qualidade de vida da população e no setor econômico, a mobilidade urbana é palco de constantes debates que buscam seu aprimoramento com novas tecnologias (SOUZA, 2019).

Para se sugerir uma melhoria e/ou implantação de novas tecnologias no setor de transporte, é necessário que estas sejam precedidas de estudos que justifiquem tais alteraçóes. Essas justificativas originam-se de estudos com base em análises estatísticas do comportamento da populaçáo, os quais, por sua vez, buscam identificar os pontos de deficiência de algum modal de transporte ou orientar a formulação de políticas que favoreçam um modal em específico.

O avanço das ferramentas computacionais que estudam o espaço geográfico permitiu a combinação de dados estatísticos e espaciais. Essas ferramentas são chamadas de geoprocessamento, e incluem, entre outras atividades, a geração de mapas temáticos de determinado espaço geográfico em um software. A união dessas técnicas matemáticas e computacionais, além dos dados estatísticos, é o que compóe o Sistema de Informaçôes Geográficas (SIG) (FRANCISCO, 2014).

Novas técnicas de geoprocessamento e ferramentas nos sistemas SIG permitiram que os dados estatísticos passassem a ser analisados de forma espacial, o que facilitou a visualização de caraterísticas importantes das informações coletadas, o que ocorreu, por exemplo, no estudo realizado pelo Dr. John Snow, em Londres, em 1854, para identificar poços d'água contaminados e conter uma epidemia de cólera (PAMBOUKIAN, 2015). 
A união de dados estatísticos com o geoprocessamento possibilitou a identificação de regióes de interesse na análise realizada, como em locais de maior densidade demográfica de uma cidade. No setor dos transportes, a união dessas técnicas possibilitou diversas análises que podem levar à implantação de um modal novo, como uma nova linha do Metrô, ou à identificação de deficiências em um modal já existente. Outro possível resultado é a identificação de polos geradores de tráfegos em regióes da cidade caracterizadas por serem o destino ou a origem de uma parcela grande da populaçáo. Por esses polos concentrarem um grande fluxo de pessoas, sua identificação e caracterização são relevantes, uma vez que os usuários precisam utilizar pelo menos um modal para se locomover até o destino.

Na Região Metropolitana de São Paulo (RMSP), a Companhia do Metropolitano de São Paulo (Metrô) realiza a pesquisa Origem-Destino (OD), a qual aborda não apenas os pontos iniciais e finais do deslocamento, mas também fatores socioeconômicos dos usuários, os modais utilizados, o tempo de viagem, os horários, entre outros dados. Esses dados resultantes da pesquisa OD alimentam as técnicas de geoprocessamento de modo a atribuir informaçóes em um dado ponto espacial. O mapa gerado pela união dessas informaçóes pode auxiliar a tomada de decisão no planejamento urbano (FRANCISCO, 2014).

O estudo georreferenciado dos dados possibilita visualizar a posiçáo de origem ou destino e correlacionar ao modal utilizado, sendo possível verificar se a escolha do modal está relacionada à oferta de transporte público, ao conforto ou à distância (FRANCISCO, 2014). Estudar um polo gerador de tráfego pode permitir a avaliação do perfil de transporte urbano e a identificação de falhas ou regióes que precisam de melhorias no setor de transporte, além de fornecer informaçóes para o planejamento urbano. O campus Higienópolis da Universidade Presbiteriana Mackenzie (UPM) é um polo gerador de tráfego, tendo uma área construída de $110 \mathrm{mil} \mathrm{m}^{2}$ com um número aproximado de 40 mil pessoas por dia (UNIVERSIDADE PRESBITERIANA MACKENZIE, 2019). Com esses dados em mente, questiona-se: é possível analisar o perfil de deslocamento dos alunos da Escola de Engenharia da UPM georreferenciando os dados obtidos de modo a observá-los de uma maneira espacial em função da escolha do modal de transporte?

Dessa forma, o objetivo desta pesquisa é caracterizar a Escola de Engenharia da UPM como um polo gerador de tráfego em termos dos deslocamentos de seus alunos, tendo como origem ou destino esse local, bem como detalhar os modais de transporte utilizados. 


\section{METODOLOGIA}

Para o estudo, foi feita, primeiramente, uma triagem dos dados da pesquisa realizada por Oliveira e Cymrot (2017), separando-se os dados que poderiam ser tratados em um software de SIG, restringindo a pesquisa aos 350 questionários respondidos pelos alunos que informaram o endereço - a posição geográfica do aluno é imprescindível para o georreferenciamento das informaçôes. Após a triagem da posição geográfica, a segunda etapa do processo buscava agrupar as informaçóes de acordo com o modal de transporte utilizado pelos alunos em sua origem e seu destino. Também nessa triagem foi excluído o modal bicicleta por não ter apresentado grande volume de respostas. Uma terceira seleção foi realizada para agrupar os alunos que presenciaram ou sofreram assédio sexual no transporte público.

Com os agrupamentos dos dados realizados e utilizando como mapa-base a RMSP e o traçado das linhas de metrô e da Companhia Paulista de Trens Metropolitanos (CPTM), extraídos dos sites de órgãos públicos (SÃO PAULO, 2019b), foram gerados no software QGIS versão 2.18 oito mapas distintos que possibilitaram a identificação das áreas de utilização de cada modal analisado e os fatores espaciais que possam justificar a preferência pelo modal utilizado, como distância e falta de oferta de transporte público.

Para a elaboração desses mapas, foram utilizadas ferramentas do software que possibilitaram melhorar a exposição dos dados estatísticos, tais como a geração de mapas de calor ou mapas de Kernel, que é um método estatístico para a plotagem de curvas de densidades nos quais se pondera os dados com um referencial estabelecido (MEDEIROS, 2015; BARROS, 2018). Outro método foi a utilização de raios de distâncias, criados a partir da ferramenta Buffer, que consiste na geração de raios com distâncias preestabelecidas que permite classificar os pontos geográficos em relação a um referencial, a UPM, no caso desta pesquisa.

Com todos os mapas gerados, foi realizada uma comparação daqueles que tinham o mesmo modal, buscando identificar as diferenças nas posições de origem e destino, permitindo identificar e analisar as regiôes de alta concentração.

\section{FUNDAMENTAÇÃO TEÓRICA}

O aumento populacional nas megalópoles contribuiu para que o deslocamento da população se tornasse um problema de gestáo, uma vez que intensos congestionamentos 
e a perda de tempo no trajeto afeta a qualidade de vida de todos. Dados disponibilizados a partir de pesquisas quantitativas sobre o setor de transporte de uma cidade ou de uma região podem tornar o planejamento do setor mais eficiente (SÃO PAULO, 2008).

A pesquisa $\mathrm{OD}$, realizada pelo Metrô, revela dados que possibilitam a criação de simulaçóes e análises da condição real da RMSP, permitindo a avaliação de futuros projetos e políticas para a restruturação da rede de transporte já existente. A pesquisa OD é realiza a cada dez anos e busca coletar informaçóes atualizadas a respeito das viagens geradas pela população da RMSP, de modo a classificá-las em modais de transportes, horários típicos, motivos da viagem, entre outros, possibilitando diversas combinaçôes para abastecer o planejamento da mobilidade urbana (SÃO PAULO, 2008).

Por meio de dados coletados na pesquisa OD de 2007 foi possível estabelecer a participação de cada modal de acordo com a classificação dos transportes motorizados. Assim, em comparação à pesquisa OD de 1997, foi possível constatar descritivamente um leve aumento do uso do modal Metrô. Já o modal carro, que em 1997 teve a participação de 47\%, diminuiu para 41\%, em 2007; apesar da queda, ainda permanece com a maior participação no grupo dos transportes motorizados (SÃO PAULO, 2008). Ressalta-se que as estatísticas permitem a observação das mudanças, contudo, quando se inclui os dados espaciais, é possível também identificar especificamente as regióes em que ocorreram as mudanças.

A geração de mapas temáticos com os dados coletados auxilia na visualização da situação atual da região, ocasionando a implantação de um planejamento mais adequado. Por exemplo, na pesquisa OD de 2007, foram gerados dois mapas temáticos para a densidade de viagens motorizadas, um para o ano de 1997 e outro para 2007, possibilitando observar que as viagens motorizadas aumentaram de acordo com o aumento populacional dessas regióes (Figura 1).

$\mathrm{Na}$ pesquisa OD de 2017, foi contabilizado um total de 42 milhóes de viagens produzidas por dia. Em relaçáo à pesquisa de 2007, houve um aumento de 10,3\% na geração de viagens. A realização da pesquisa periodicamente possibilita observar a alteração nos modais de transporte da populaçáo, como na pesquisa de 1977 , a primeira a considerar o modal bicicleta, o qual representou 1,2\% do total de viagens. Já na pesquisa de 1997, o mesmo modal representou 1,5\% do total de viagens; em 2007, representou 2,4\% do total de viagens; e, em 2017, o modal representou 2,7\% do total de viagens (SÃO PAULO, 2019a). 

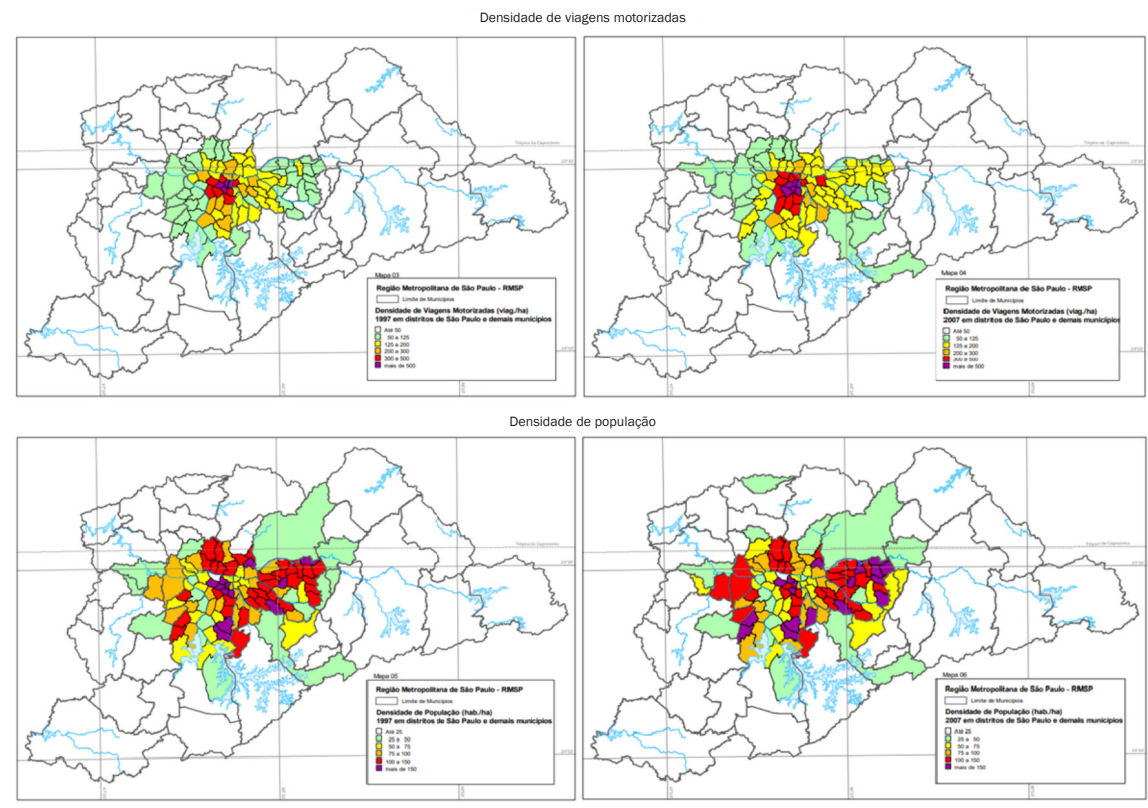

Figura 1 Mapas temáticos da pesquisa OD 2007.

Fonte: São Paulo (2008).

A realização de pesquisas referentes ao deslocamento da população em metrópoles, a exemplo da própria pesquisa OD do Metrô de São Paulo, é extremamente importante para o fornecimento de dados relativos à mobilidade urbana e ao comportamento do deslocamento da população. Os grandes empreendimentos nas metrópoles, como teatros, universidades e centros comerciais, atraem grande quantidade de pessoas. Desse modo, torna-se interessante a realização de estudos de mobilidade urbana nessas regióes, uma vez que é possível classificar os modais de transporte utilizados por seus usuários e identificar os modais poucos utilizados (CYBIS; LINDAU; ARAÚJO, 1999).

A UPM está localizada no distrito da Consolação, região central da cidade de São Paulo, também pertencente à zona censitária da Vila Buarque. A região apresenta uma grande oferta de transporte público, contando com linhas de Metrô, corredores de ônibus, ciclofaixas, entre outras modalidades (SÃO PAULO, 2019b).

Oliveira e Cymrot (2017) realizaram uma pesquisa com os alunos dos cursos de Engenharia da UPM sobre os modais de transporte utilizados nos seus deslocamentos, tendo como origem ou destino a universidade. Os autores elaboraram e aplicaram um questionário anônimo que investigava variáveis como "curso, idade, sexo, tempo médio gasto em deslocamento, quilometragem percorrida, modais utilizados, horários de 
chegada e partida, endereços de origem e destino do deslocamento, entre outros" (OLIVEIRA; CYMROT, 2017, p. 8).

Entre a população de 4934 alunos, foram amostrados 395 alunos (cerca de 8\% dos alunos) que responderam ao questionário. A amostragem foi por acessibilidade, sendo sorteadas as turmas nas quais a pesquisa seria realizada em sala de aula, considerando-se no sorteio das turmas as variáveis curso e turno para segmentaçáo. Os alunos podiam assinalar mais de um modal de transporte usado em cada deslocamento. Obteve-se como resposta que 30\% dos alunos iam a pé; 35,9\% utilizavam o metrô; $33,1 \%$, o carro; e $51,8 \%$, o ônibus. Ressalta-se que, no momento da pesquisa, a estação Higienópolis-Mackenzie do Metrô ainda não tinha sido inaugurada.

\section{RESULTADOS E DISCUSSÃO}

Os resultados foram obtidos utilizando-se os dados secundários oriundos da pesquisa de Oliveira e Cymrot (2017), a partir dos quais foram elaborados mapas utilizando o QGIS, software de geoprocessamento. O Mapa 1 foi elaborado considerando-se apenas a utilização da modalidade "a pé" como meio de deslocamento da origem até a UPM. Foram criados raios crescentes de 500 metros até 2 mil metros, utilizando a UPM como ponto central.

Com o Mapa 1, verificou-se que o aluno mais distante nessa modalidade está a 1.716 metros da UPM. Realizando-se a contagem de alunos a cada faixa de 500 metros, foi elaborado o Gráfico 1, no qual se pode evidenciar que a maior concentração de estudantes ocorre com um raio de até mil metros da UPM, destacando-se a faixa de 500 a mil metros da UPM, que apresentou a maior concentração de indivíduos nessa modalidade. 


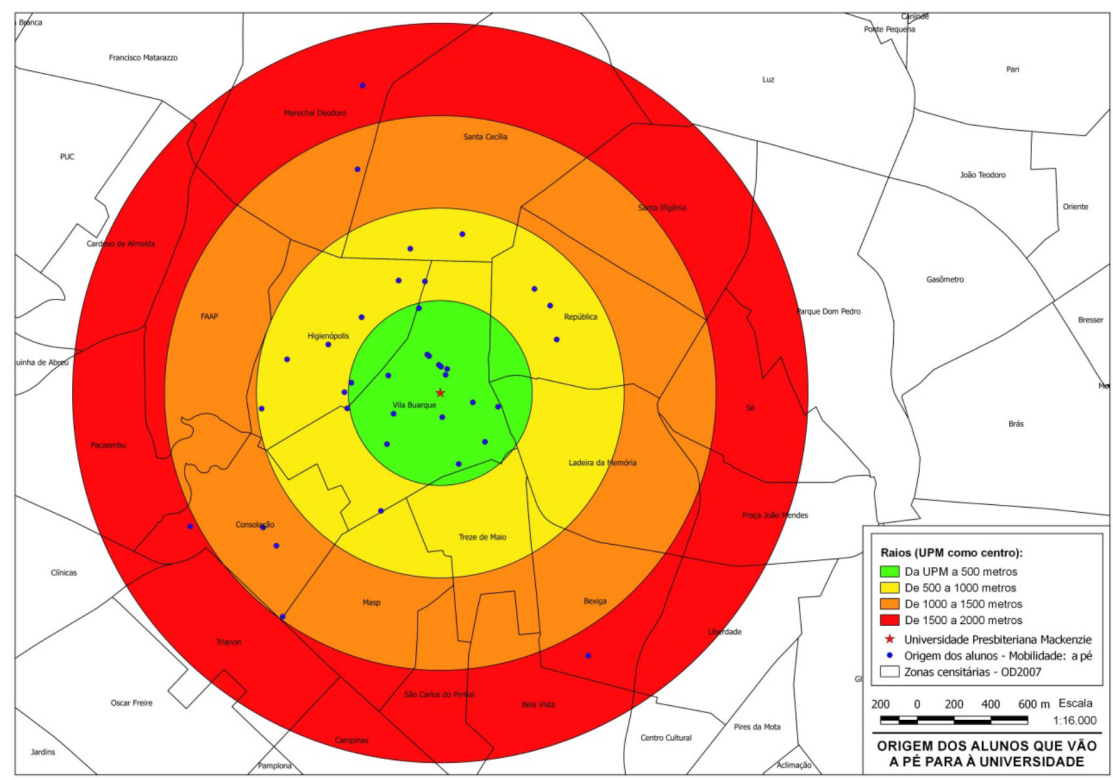

Mapa 1 Origem dos alunos que vão a pé à universidade.

Fonte: Elaborado pelos autores (2019).

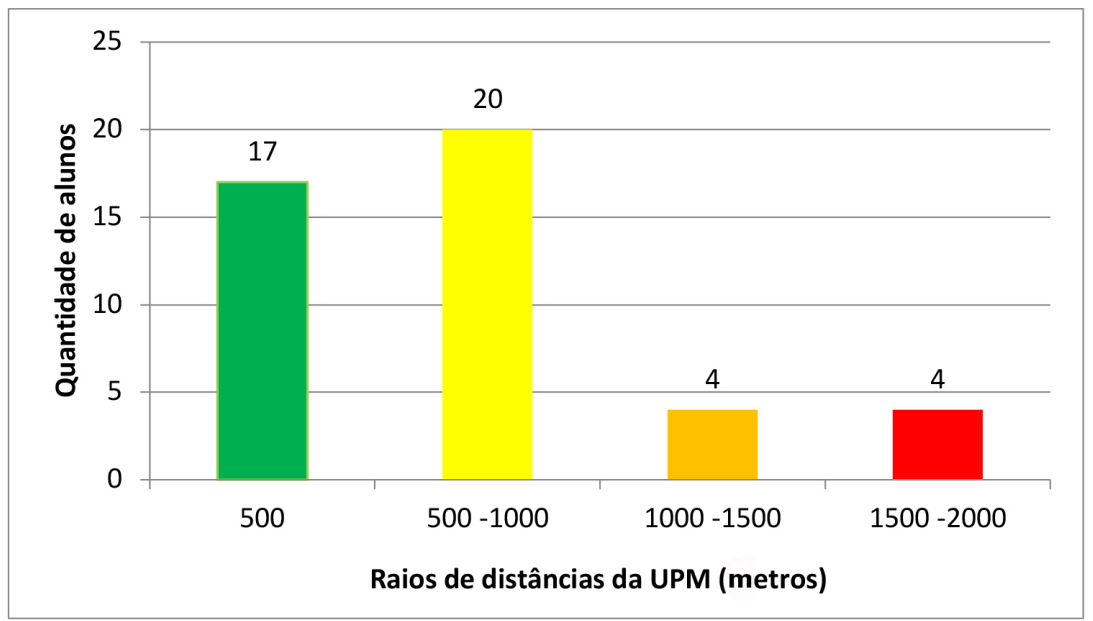

Gráfico 1 Quantidade de alunos nos raios de distâncias.

Fonte: Elaborado pelos autores (2019). 
O Mapa 2 foi elaborado a partir da resposta afirmativa dos alunos que utilizam as modalidades "Metrô", "Trem", "Ônibus" ou qualquer combinação entre esses meios de transporte.

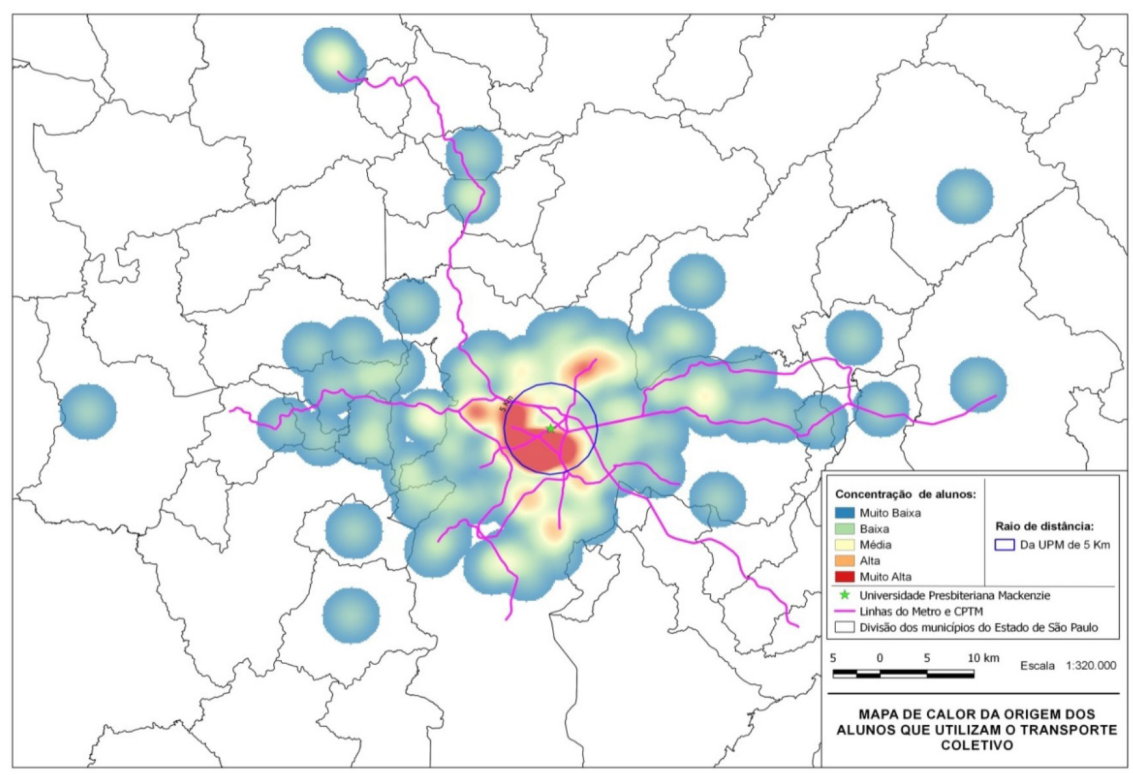

Mapa 2 Mapa de calor da origem dos alunos que utilizam o transporte coletivo.

Fonte: Elaborado pelos autores (2019).

Pode-se constatar que a maior concentração de alunos está a um raio de 5 mil metros da UPM. Há algumas regióes de alta concentração isoladas (cor vermelha e laranja) fora desse raio, mas que estão próximas ao sistema metroviário ou ferroviário.

A partir das respostas sobre o assédio sexual aos estudantes que utilizam o transporte coletivo (OLIVEIRA; CYMROT, 2017), elaborou-se o Mapa 3, que indica a concentração de alunos que relataram terem sofrido ou presenciado assédio sexual no transporte coletivo. Ressalta-se que $91,2 \%$ das pessoas que responderam "sim" são do sexo feminino. Calculou-se que $77,2 \%$ dos alunos que relataram assédio sexual se 
encontram na cidade de São Paulo. Observam-se quatro altas concentraçôes, a maior delas encontra-se próxima à região central da cidade de São Paulo dentro de um raio de 5 quilômetros da UPM e localizada na região da avenida Paulista entre as zonas censitárias Ana Rosa e Clínicas. Já as outras três estão afastadas dessa região central, sendo próximas às regiôes Campo Belo, Ceasa e Casa Verde.

A Figura 2 apresenta uma ampliação do Mapa 3, da região próxima à UPM.

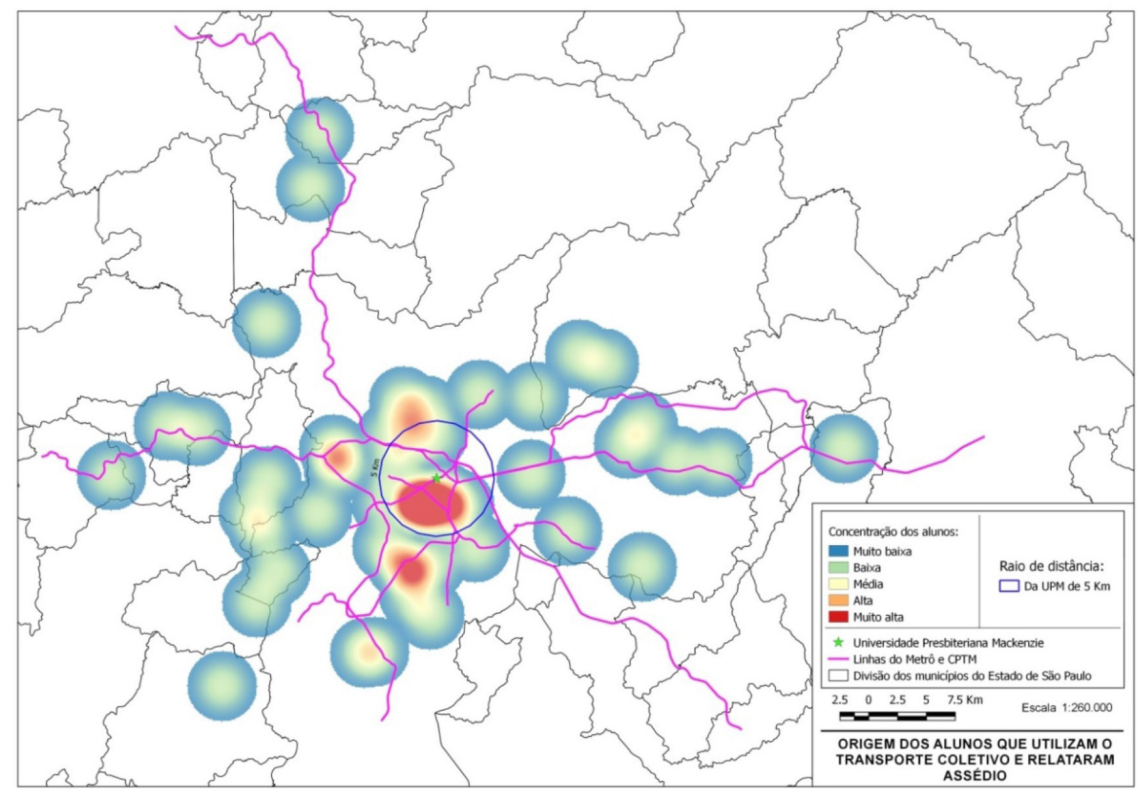

Mapa 3 Origem dos alunos que utilizam o transporte coletivo e relataram assédio sexual.

Fonte: Elaborado pelos autores (2019) 


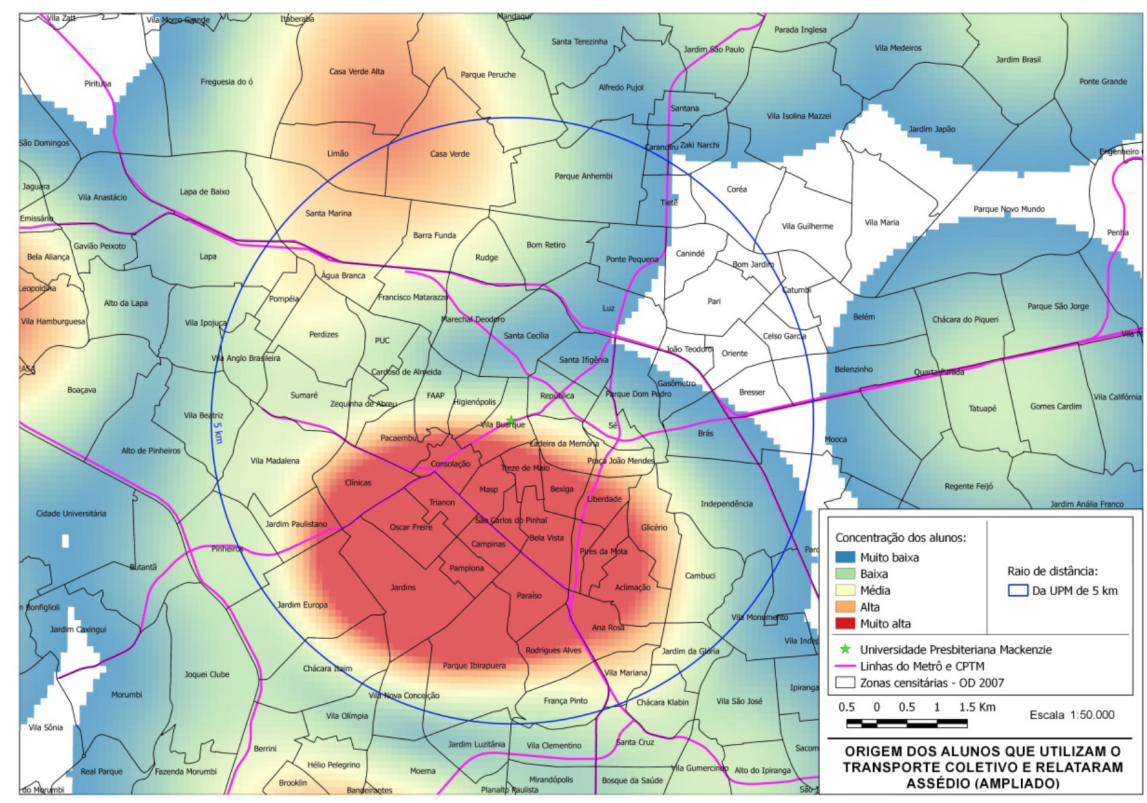

Figura 2 Ampliação do Mapa 3 da região próxima à Universidade Presbiteriana Mackenzie.

Fonte: Elaborada pelos autores (2019).

Para as respostas nas modalidades "Carro" ou "Moto" (OLIVEIRA; CYMROT, 2017), alocaram-se os pontos para gerar um mapa de calor (Mapa 4), junto às linhas do Metrô e da CPTM.

Analisando o Mapa 4, pode-se observar uma pequena região (sinalizada na cor vermelha) com maior concentração de alunos que se deslocam do centro da cidade de São Paulo, próximo à universidade. Há áreas de menor concentração (sinalizadas nas cores amarela e verde) na regiāo central expandida para as zonas Norte, Oeste e Sul da cidade de São Paulo, e em cidades próximas (regiáo metropolitana), em que a localização dos alunos fica longe das linhas da CPTM. A partir do levantamento dos pontos no Mapa 2, ressalta-se que $80 \%$ dos alunos que utilizam o transporte coletivo estão na cidade de São Paulo. 


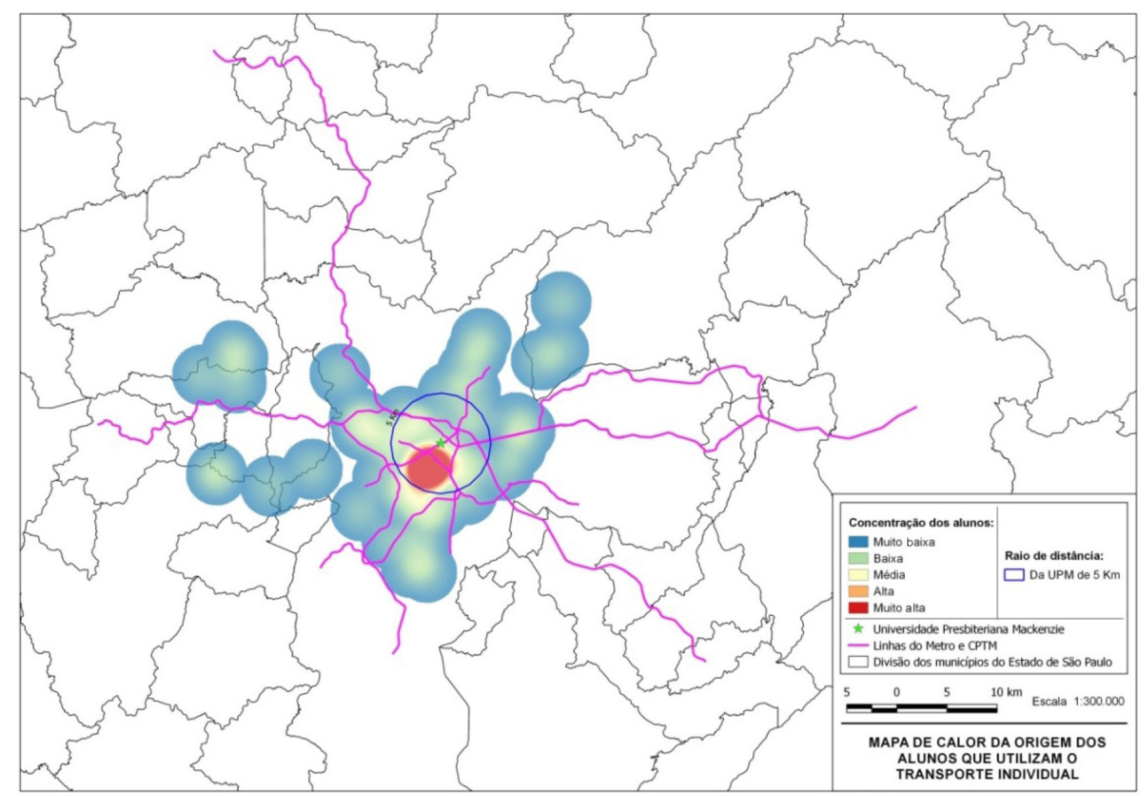

Mapa 4 Mapa de calor da origem dos alunos que utilizam o transporte individual.

Fonte: Elaborado pelos autores (2019).

Com base nas respostas positivas de alunos que utilizavam o transporte individual como meio principal e que relataram ter presenciado ou sofrido assédio sexual no transporte público (OLIVEIRA; CYMROT, 2017), foi elaborado o Mapa 5. Calculou-se que $30,6 \%$ dos alunos relataram assédio sexual e, desse total, $81,2 \%$ são do sexo feminino. Esses relatos encontram-se dentro do raio de 5 mil metros da UPM, que se compreendem as zonas censitárias: Jardins, Pamplona, Paraíso, Trianon e Oscar Freire, observado na Figura 3 uma ampliação do Mapa 5. 


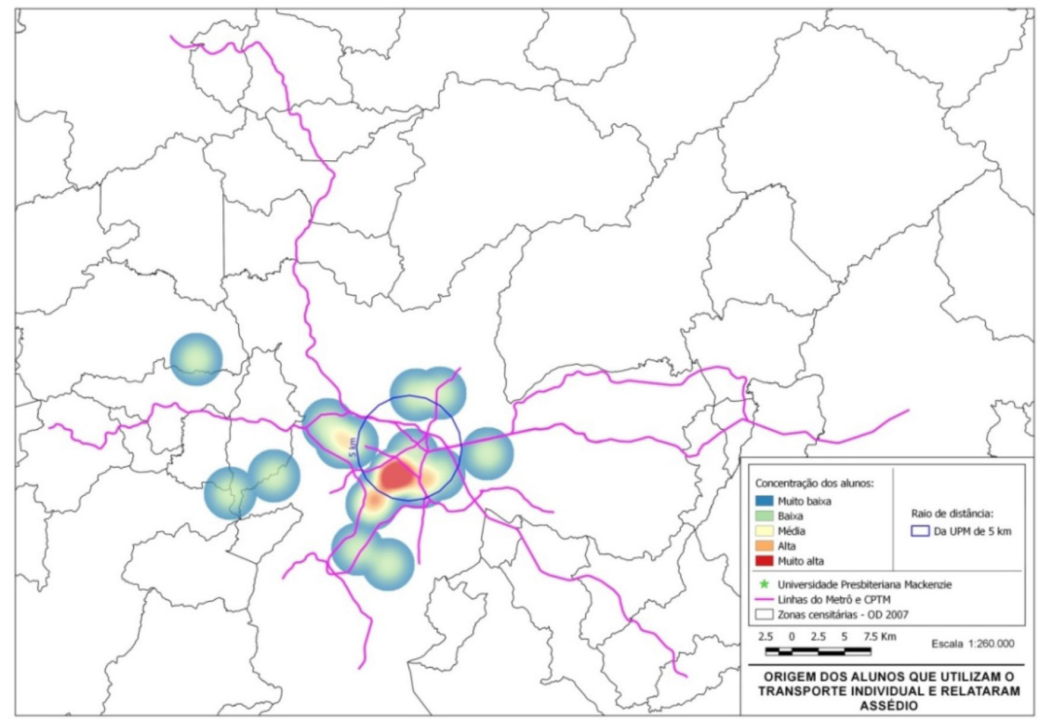

Mapa 5 Origem dos alunos que utilizam o transporte individual e relataram assédio sexual. Fonte: Elaborado pelos autores (2019).

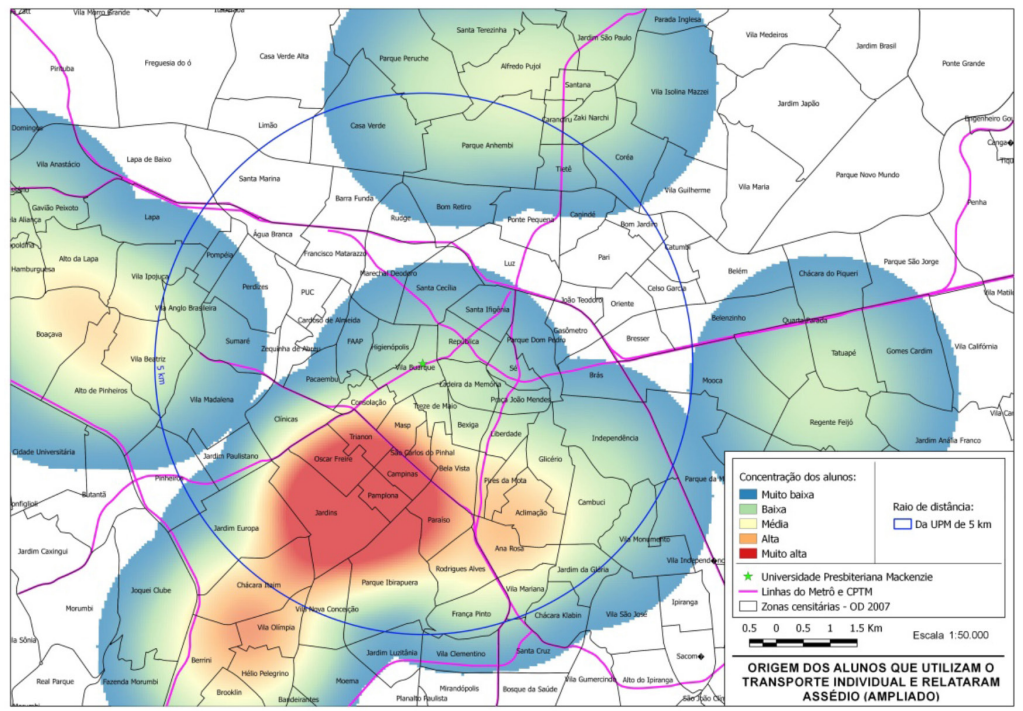

Figura 3 Ampliação do Mapa 5 da região próxima à Universidade Presbiteriana Mackenzie.

Fonte: Elaborada pelos autores (2019). 
O Mapa 6 foi elaborado a partir das respostas de alunos que utilizam o transporte individual, buscando alguma relação entre a localização da origem e a escolha do transporte individual. Para isso, foi criada uma faixa de 1.000 metros para cada lado no entorno das linhas do Metrô e da CPTM.

Com base no Mapa 6 e nas análises feitas, pode-se notar que apenas 36,1\% dos alunos que utilizam o transporte individual estão alocados na faixa de 1.000 metros. Outro fato a ser ressaltado é que $86,1 \%$ dos alunos que utilizam o transporte individual estão na cidade de São Paulo.

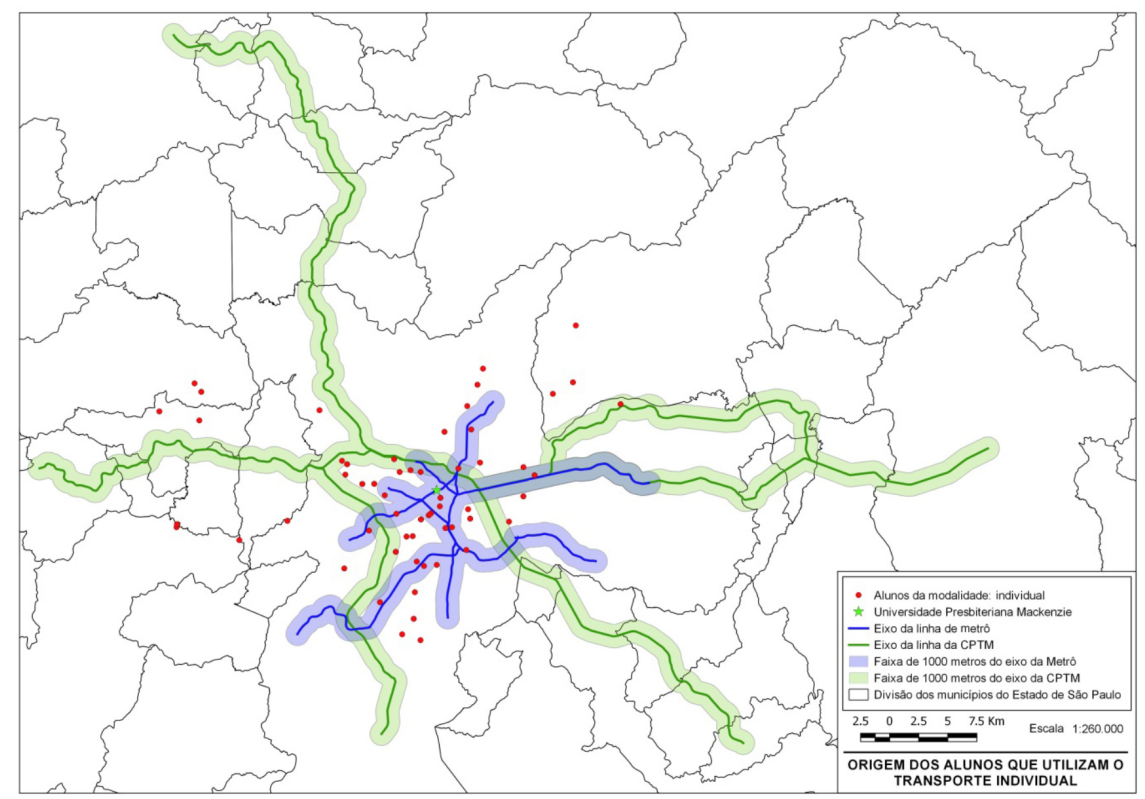

Mapa 6 Origem dos alunos que utilizam o transporte individual.

Fonte: Elaborado pelos autores (2019)

O Mapa 7 foi elaborado a partir dos alunos que afirmaram o uso da modalidade "Metrô", "Trem" ou ambos. Houve respostas de alunos que informaram que também utilizam ônibus. Os alunos que apenas utilizam ônibus foram excluídos, pois a análise levou em consideração apenas os usuários do transporte metroviário e/ou ferroviário. Foi criada uma faixa de 1.000 metros para cada lado no entorno das linhas do Metrô e da CPTM, o que significa distância suficiente para o acesso dos usuários nessas modalidades. 


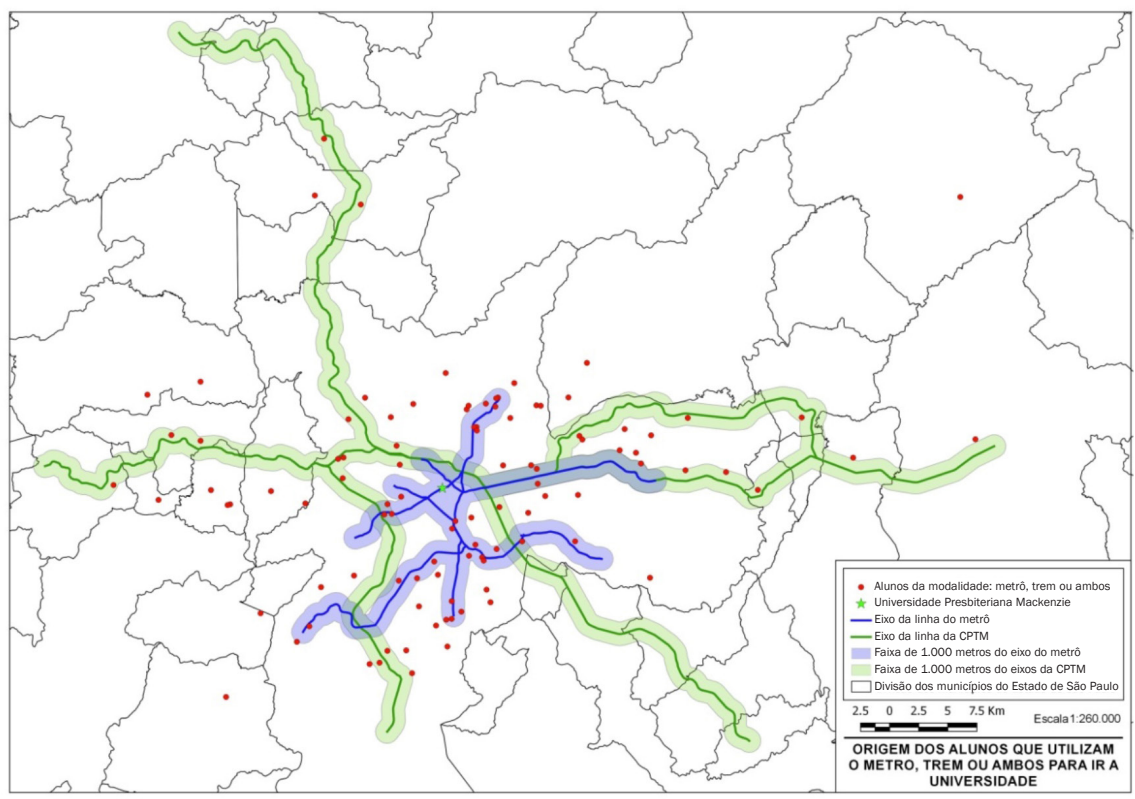

Mapa 7 Origem dos alunos que utilizam o metrô, trem ou ambos para ir à universidade.

Fonte: Elaborado pelos autores (2019).

Observando o Mapa 7, pode-se constatar que os pontos se concentram próximos da faixa ou ao redor dela, com exceção de alguns alunos que estão locados distantes das linhas do Metrô e/ou CPTM, mas próximos ao eixo da estação-terminal. Realizando as contagens dos pontos dentro da faixa, verificou-se que $50,49 \%$ dos alunos nessa modalidade estáo locados dentro dos 1.000 metros das linhas de transportes, conforme o Gráfico 2. 


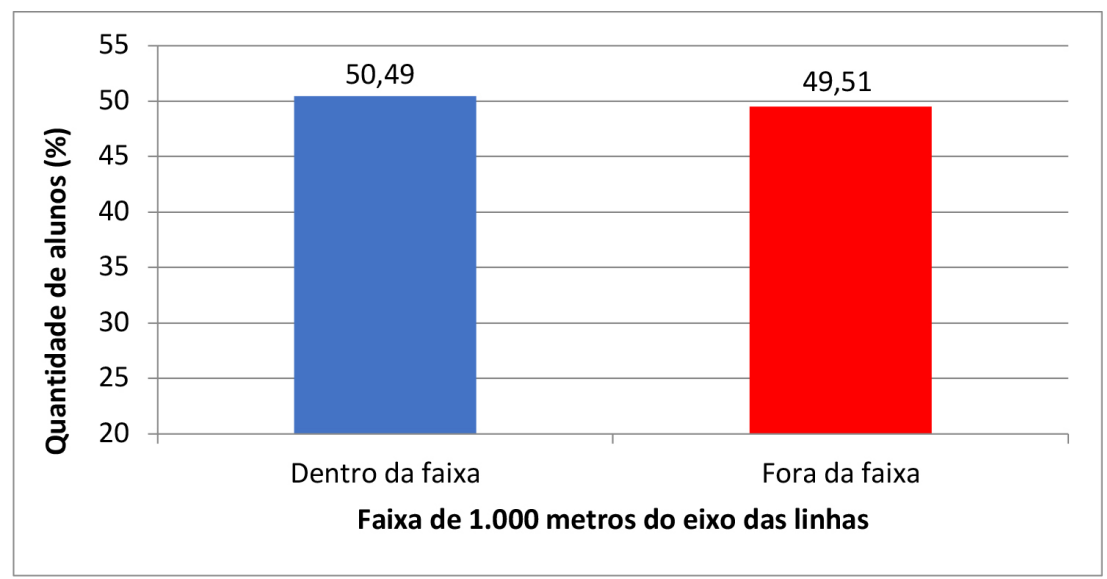

Gráfico 2 Quantidade de alunos em relação à faixa de 1.000 metros do eixo das linhas do metrô e da CPTM.

Fonte: Elaborado pelos autores (2019).

A análise referente aos destinos dos alunos foi baseada em dois mapas (mapas 8 e 9), utilizando-se a informação das modalidades transporte coletivo ou individual. Para transporte coletivo foi considerada a resposta de alunos que afirmaram utilizar "Metrô", "Trem", "Ônibus" ou qualquer combinação entre eles. Para o transporte individual foi considerada a resposta nas modalidades "Carro" ou "Moto". Foi elaborado um mapa de calor para cada modalidade, para apresentar a concentração regional dos alunos. 


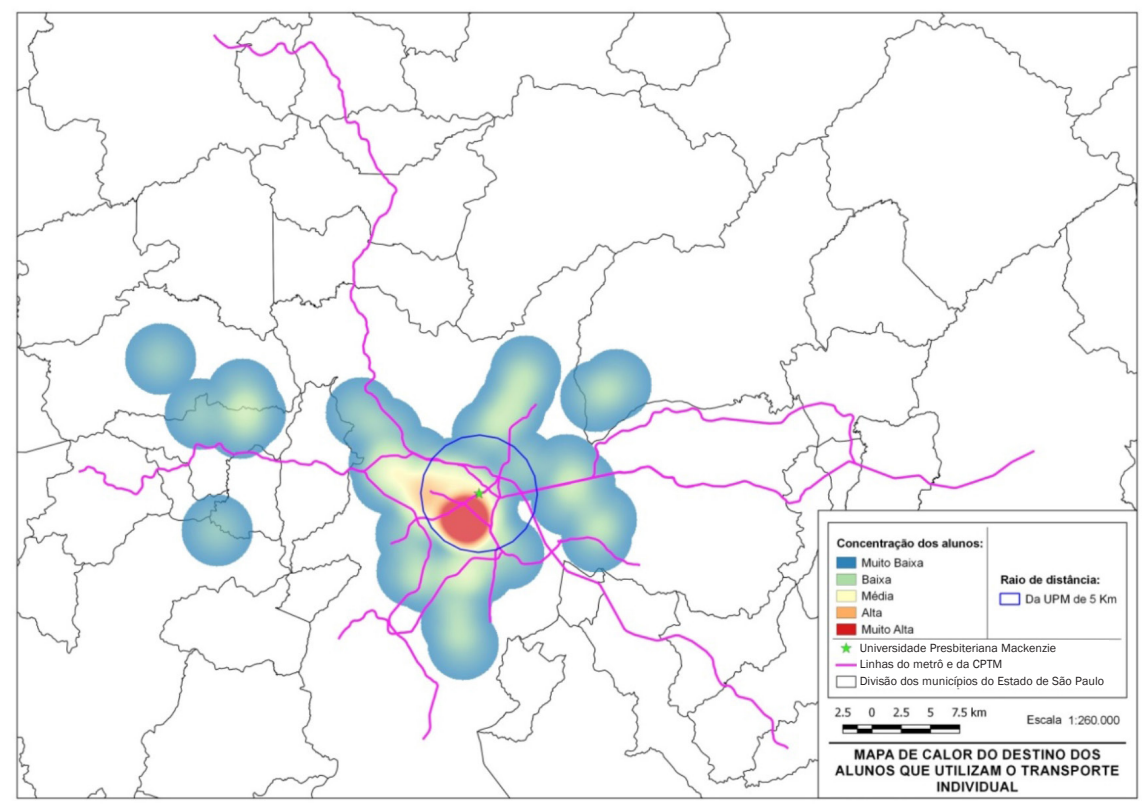

Mapa 8 Mapa de calor do destino dos alunos que utilizam o transporte individual.

Fonte: Elaborado pelos autores (2019).

Para os alunos que utilizam o transporte individual no Mapa 8, não houve, aparentemente, mudança relevante em relaçáo ao mapa de calor da modalidade cujos dados oriundos foram do Mapa 4.

$\mathrm{Na}$ modalidade de transporte coletivo, no Mapa 9, também não houve grandes alteraçóes em relação ao mapa de calor, gerado a partir dos dados da origem (Mapa 2). Cabe ressaltar que ocorreu um aumento na utilização da modalidade na região Norte da cidade de São Paulo, próximo à Linha 01 - Azul do Metrô. 


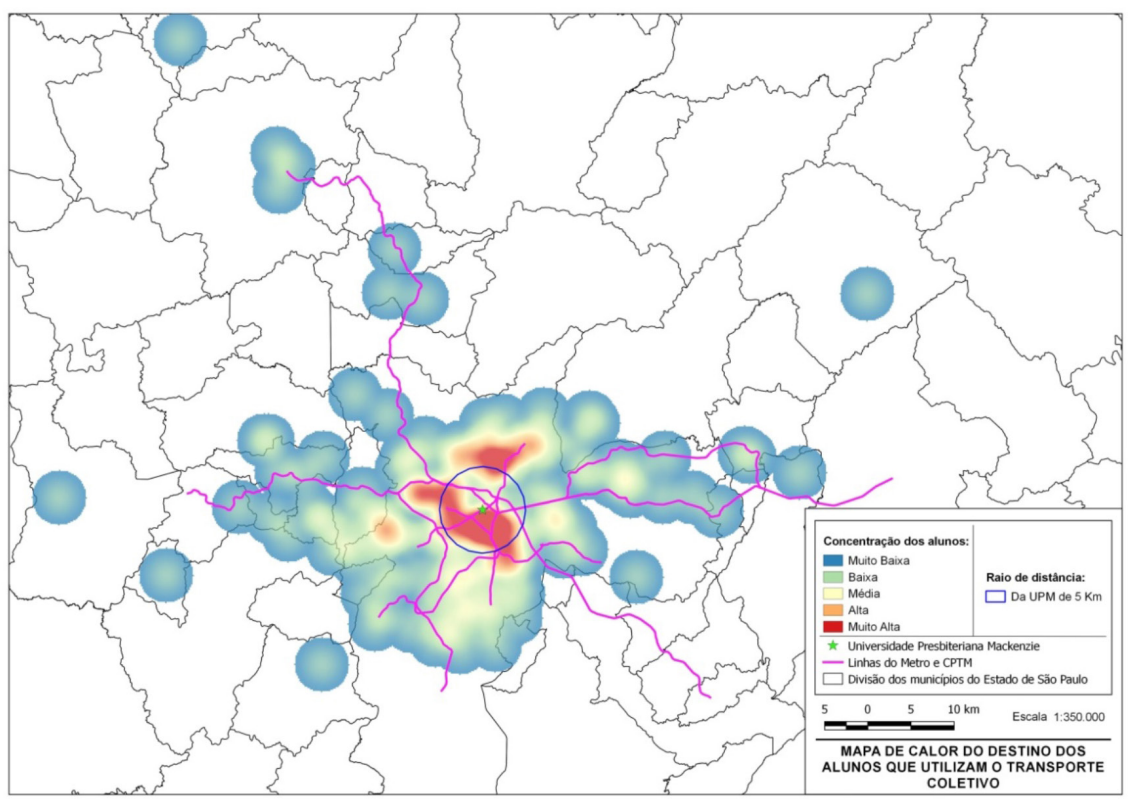

Mapa 9 Mapa de calor do destino dos alunos que utilizam o transporte coletivo.

Fonte: Elaborado pelos autores (2019).

\section{CONSIDERAÇÓES FINAIS}

O uso de um SIG para a análise de dados de uma pesquisa possibilita visualizar a distribuição dos dados sobre a área em estudo. Tal procedimento facilita o planejamento de futuras implantaçóes e reestruturaçóes da rede de transporte. Pesquisas como a de Oliveira e Cymrot (2017) utilizada neste georreferenciamento e a pesquisa OD realizada a cada dez anos são exemplos de levantamentos de dados que permitem alimentar os softwares do sistema de SIG, resultando em dados espaciais georreferenciados e possibilitando a construção de mapas temáticos.

Com esta pesquisa, foi possível observar aspectos sobre os alunos do modal "a pé" no trajeto de ida para a universidade, sendo a distância máxima de aproximadamente $2 \mathrm{~km}$ e a maior concentração de alunos está a um raio de $1 \mathrm{~km}$ da universidade. Já os 
alunos que utilizam o modal Metrô, CPTM ou ambos têm maioria dentro de uma faixa de $1 \mathrm{~km}$ das linhas dos modais e os que não estão dentro dessa faixa permanecem próximos às linhas ou próximos às estaçôes terminais. Também foram feitas comparaçôes entre os modais coletivo e individual para identificar características entre eles. Para o modal coletivo, pode-se observar que a maior concentração de usuários está localizada na região central da cidade de São Paulo, com pontos isolados localizados nos extremos das linhas de Metrô e CPTM.

Para o modal individual, permaneceu uma maior concentração única na região central de São Paulo. Esse modal não apresentou pontos isolados como o coletivo. Observou-se, também, que a maioria dos usuários desse modal está dentro do município de São Paulo e próximos de linhas do Metrô e da CPTM, no entanto, os pontos fora do município de São Paulo estão localizados distantes das linhas de transporte, justificando a utilização desse modal.

O formulário da pesquisa, elaborado por Oliveira e Cymrot (2017), questionou usuários do transporte coletivo sobre assédio sexual (se eles sofreram ou presenciaram situações dessa natureza). Com a utilização do georreferenciamento foi possível observar que uma regiáo do município de São Paulo concentrou grande parte dos alunos que relataram assédio sexual para ambos os modais coletivo e individual, sendo a região compreendida pelas zonas censitárias: Aclimação, Ana Rosa, Bela Vista, Campinas, Centro Cultural, Consolação, Jardins, Masp, Oscar Freire, Pamplona, Paraíso, São Carlos do Pinhal, Trianon e Rodrigues Alves.

Essas análises são exemplos do uso do geoprocessamento na visualização dos dados estatísticos coletados. Os dados aqui apresentados revelam a importância das pesquisas de mobilidade urbana na tomada de decisão dos gestores para a implementação de novos projetos, como a expansão das linhas existentes para atender aos bairros mais periféricos, e políticas públicas, como propagandas interativas de conscientização com os usuários. A realização periódica de pesquisas de mobilidade urbana mantém as açóes públicas atualizadas com as mudanças do comportamento da população.

Em pesquisas futuras, sugere-se a inclusão do patinete elétrico como possível modal de transporte, visto que nos últimos anos a sua participação vem crescendo na cidade de São Paulo em regiôes de grandes deslocamentos de pessoas, e uma análise mais profunda do modal bicicleta, que também apresenta um crescimento em sua utilização. Além disso, sugere-se também a pesquisa periodicamente dos polos gerados de tráfego da RMSP e a ampliação para as zonas censitárias com os dados da pesquisa OD do Metrô de São Paulo, uma vez que o transporte público se torna mais eficaz ligando os bairros residenciais a essas regióes de grande fluxo de pessoas. 


\title{
GEORREFERENCED STUDY OF THE DISPLACEMENT PROFILE OF STUDENTS FROM A PRIVATE UNIVERSITY
}

\begin{abstract}
Urban mobility is increasingly becoming a problem for large metropolises since the time spent on displacing the population affects their quality of life and economy in the region. To reduce travel time, transportation management needs to provide information and respect the population's travel profile to make decisions about future projects or improve the existing network. Based on statistical information and the use of geoprocessing software, such as the Geographic Information Systems (GIS), enabling a better response and identification of transport traffic regions or another factor that influences mobility, such as security and supply public transport. In the Metropolitan Region of São Paulo (RMSP), a Source-Destination survey is conducted to collect data related to the characteristics of the population and their displacement profile. For this article, a research carried out by Oliveira and Cymrot (2017) on the displacement profile of a private university was used as a secondary source of data, as student location, mode of modal use, and affirmative or negative relational use on sexual harassment in the public transportation. From the collected statistical data, we seek to complement them with the georeferencing of some information, allowing a better response. QGIS software version 2.18 was used to perform the georeferencing, which allowed the creation of maps in this way, facilitating the characterization of a traffic generating pole. The generated maps allow analyzing the students' position, relating their distance to the university and the subway or rail system, in addition to observing more easily the regions of high concentration of students in the different modes.
\end{abstract}

Keywords: Georeferencing. Urban mobility. University.

\section{REFERÊNCIAS}

BARROS, J. Criando mapa de calor no QGIS. Blog Geoaplicada, 6 nov. 2018. Disponível em: https://www.geoaplicada.com/blog/criando-mapa-de-calor-no-qgis/. Acesso em: 20 jul. 2019.

CYBIS, H. B. B.; LINDAU, L. A.; ARAÚJO, D. R. C. de. Avaliando o impacto atual e futuro de um polo gerador de tráfego na dimensão de uma rede viária abrangente. Revista Transportes, Porto Alegre, v. 7, n. 1, p. 64-85, abr. 1999. Disponível em: https://www.revistatransportes.org.br/anpet/article/view/220/189. Acesso em: 13 ago. 2021. 
FRANCISCO, C. N. Sistemas de Informaçôes Geográficas: estudo dirigido em SIG. 2. ed. rev. Niterói: Universidade Federal Fluminense, 2014. Disponível em: https://www.capacidades. gov.br/blog/download/id/38/post $/ 410 / \mathrm{midia} / 9901 \#:-$ :text=Os\%20Sistemas $\% 20 \mathrm{de} \% 20$ Informa\%C3\%A7\%C3\%A3o\%20Geogr\%C3\%A1fica,et\%20al.\%2C\%202005. Acesso em: 10 jun. 2019.

MEDEIROS, A. M. L. de. Mapas de Kernel: conceitos e aplicaçôes. Slideshare, 8 jul. 2015. Disponível em: https://pt.slideshare.net/AndersonMedeiros/mapas-de-kernel-conceitos-e-aplicaes. Acesso em: 20 jul. 2019.

OLIVEIRA, C. S.; CYMROT, R. Perfil de deslocamento urbano diário de alunos de uma universidade privada. In: JORNADA DE INICIAÇĀO CIENTÍFICA, 13., MOSTRA DE INICIAÇÃO TECNOLÓGICA, 7., 2017, São Paulo. Anais [...]. São Paulo: Programa Institucional de Iniciação Científica e Iniciação Tecnológica, 2017. Disponível em: http://eventoscopq. mackenzie.br/index.php/jornada/xiiijornada/paper/view/368. Acesso em: 10 jun. 2019.

PAMBOUKIAN, S. V. D. Análise Dr. John Snow. São Paulo: Laboratório de Geotecnologias Mackenzie, 12 maio 2015. Disponível em: https:/www.mackenzie.br/fileadmin/OLD/62/ ARQUIVOS/PUBLIC/user_upload/_imported/fileadmin/LABGEO/Curso/01._Aula_ 01/0107._Analise_Dr._John_Snow.pdf. Acesso em: 10 jun. 2019.

SÃO PAULO (Estado). Secretaria dos Transportes Metropolitanos. Pesquisa Origem e Destino 2007. São Paulo, 2008. Disponível em: http://www.metro.sp.gov.br/pesquisa-od/resultadodas-pesquisas.aspx. Acesso em: 15 jul. 2019.

SÃO PAULO (Estado). Secretaria dos Transportes Metropolitanos. Pesquisa Origem e Destino 2017. São Paulo, 2019a. Disponível em: https://transparencia.metrosp.com.br/dataset/pesquisa-origem-e-destino/resource/4362eaa3-c0aa-410a-a32b-37355c091075. Acesso em: 26 fev. 2020.

SÃO PAULO (Prefeitura). Mapa digital da cidade de São Paulo. 2019b. Disponível em: http:// geosampa.prefeitura.sp.gov.br/PaginasPublicas/_SBC.aspx. Acesso em: 20 jul. 2019.

SOUZA, E. O papel da mobilidade urbana no acesso à cidade. Archdaily Brasil, 20 ago. 2019. Disponível em: https://www.archdaily.com.br/br/923924/a-relacao-entre-mobilidade-urbanae-acesso-a-cidade. Acesso em: 18 nov. 2019.

UNIVERSIDADE PRESBITERIANA MACKENZIE. Relatório Anual 2019: institucional e sustentabilidade. São Paulo, 2019. Disponível em: https://www.mackenzie.br/s/relatorio/anual/2020/pt/index.html\#nossagestao. Acesso em: 8 set. 2021.

\section{Contato}

Sergio Vicente Denser Pamboukian

sergio.pamboukian@mackenzie.br

\section{Tramitação}

Recebido em novembro de 2020

Aprovado em abril de 2021. 